Article

\title{
Robots Working with Humans or Humans Working with Robots? Searching for Social Dimensions in New Human-Robot Interaction in Industry
}

\author{
António B. Moniz ${ }^{1,2, *}$ and Bettina-Johanna Krings ${ }^{2}$ \\ 1 CICS.NOVA, Faculty of Sciences and Technology, University Nova of Lisbon, Campus Caparica, \\ 2829-516 Caparica, Portugal \\ 2 Institute for Technology Assessment and Systems Analysis, Karlsruhe Institute of Technology, \\ 76021 Karlsruhe, Germany; bettina-johanna.krings@kit.edu \\ * Correspondence: antonio.moniz@kit.edu or abm@fct.unl.pt; Tel.: +49-721-6082-4189
}

Academic Editor: David Karjanen

Received: 31 May 2016; Accepted: 27 July 2016; Published: 2 August 2016

\begin{abstract}
The focus of the following article is on the use of new robotic systems in the manufacturing industry with respect to the social dimension. Since "intuitive" human-machine interaction (HMI) in robotic systems becomes a significant objective of technical progress, new models of work organization are needed. This hypothesis will be investigated through the following two aims: The first aim is to identify relevant research questions related to the potential use of robotic systems in different systems of work organization at the manufacturing shop-floor level. The second aim is to discuss the conceptualization of (old) organizational problems of human-robot interaction (HRI). In this context, the article reflects on the limits of cognitive and perceptual workload for robot operators in complex working systems. This will be particularly relevant whenever more robots with different "roles" are to be increasingly used in the manufacturing industry. The integration of such complex socio-technical systems needs further empirical and conceptual research with regard to "social" aspects of the technical dimension. Future research should, therefore, also integrate economic and societal issues to understand the full dimensions of new human-robot interaction in industry today.
\end{abstract}

Keywords: human-machine interaction; manufacturing industry; cognitive workload; complex working systems; organization of work

\section{Introduction}

There is a growing notion that our society is entering a "robot society" [1]. In 2014, The Guardian told its audience that "it's increasingly common, a cliché even, for us to read about the inexorable rise of the robot as the fundamental shift in advanced economies that will transform the nature of work and opportunity within society. The robot is supposedly the specter threatening the economic security not just of the working poor but also the middle class across mature societies" [2]. The video series "Robotica" at the New York Times website [3] also revealed the variety of applications of robots in our daily life, but at the same time underlined the potentials, limits and problems that require further understanding [4]. In addition to the public interest, an increasing number of policy reports and scientific articles are being issued on these topics, indicating the rise of robots at work and in daily life of modern societies in the nearest future.

In an article published already in 1996, the Japanese scientist Masakasu Ejiri approached the future development of robotics. He verified that, "many robotics researchers believe that autonomous robots will play an important role in our future society" [5]. He particularly refers to work environments 
where most types of robots are being used. The researcher from the famous Hitachi Lab ${ }^{1}$ assumed that in the future most of the problems identified with robots will be "resolved" based on new technical options for mobility and motion control by robots as well as energy and battery developments. Indeed, these issues have been considered as major challenges in the field of industrial robotics, namely, the so-called collaborative robots. Particular research and development needs have been identified in the field of "machine reliability". Ejiri concluded, based on the state of the art at that time, which "we should direct efforts towards providing assistance to human drivers" [5]. He also assumes robotics in medical field applications to be one of the most commonly used automated systems in the future. Referring to technical assistance in surgery, Ejiri points out that "the final goal should not be an automatic surgery machine, but a machine with the capability to help a surgeon as a skilled assistant" [5]. This example refers to "imaginaries" [6] that can also be applied to robotics in general. Additionally in work environments in manufacturing, the idea of "assistance" to skilled workers becomes crucial and is still considered as the major challenge from the technical point of view.

The notion of "social" dimensions derives from the worker-robot interaction (WRI) with regard to industry safety, control systems and interface ergonomics. To a certain extent, these specifics are increasingly turning into decisive aspects of human-robot interaction (HRI) in general. HRI can be applied to developments and standards in the field of service robotics and also to all sectors in manufacturing processes. HRI, in this context, is understood as a generic field where one can include "classical" human-machine interaction (HMI) elements like communication with machines, intermediation between humans and objects, need for anticipation, simulation, etc. [7-11]. That means, system integrators, robot manufacturers and companies are increasingly aware of the need to consider "social" aspects and this does not only refer to ergonomic or safety issues. It basically refers to new qualification needs, new technical competences, and organizational competences with regard to working teams, competences in communication and decision processes within work processes. All these issues are key aspects that need to be considered when reflecting on system development in the working relation between humans and robots. Such issues, however, are mostly addressed by sociological competences. Another field of research is the field of risk analysis and safety implications of HRI addressed in the work of Thrun [12], Prewett et al. [13], and Heyer [14]. Most of them use examples from work environments. From a technical perspective, these studies take up many issues of the "social" dimension of HRI. However, these "social" issues seem to be viewed only from the perspective of technical improvements and safety.

There is a huge body of literature on issues of technical progress with regard to its social impact, both in industry sociology and in technology assessment (TA). An early TA study on "Social Impacts of Robotics" in 1982 shows how deeply the discussion on the social impact of robotics on working lives was rooted in that decade [15]. The "social issues" addressed in the discussion focused on productivity, labor, education and training needs, and international impacts. By then, only few TA studies on robotics focused on the impact on humans and society, especially in terms of employment and training needs. First studies on HMI were almost limited to ergonomics and can be assigned to research on robotics. In the field of industrial sociology, the prominent studies in the 1980s focused on the introduction of automated technology. This technology included numerical control systems, transfer machines, computerized design, and was extensively introduced in the manufacturing industry [16-19]. These studies were triggered by the discussion about technology determinism-from Veblen or Ellul [20] in the early 20th century to Blauner's work on alienation [21] or Braverman's book on deskilling [17] in the postwar decades_and later by the prominent debate about the limits of division of labor by Kern and Schumann [22]. Since then, most studies have observed the increased complexity of technical systems and concentrated on the implications of automated systems in terms of organizational changes, qualification changes, up- and deskilling processes, as well as labor market changes [17,23-25].

1 Hitachi is one of the major robot producers, and this lab is also a think tank. In Japan, such units are scientifically very sound. 
Based on empirical studies, the interdependencies between machines and work organization have been analyzed intensively and from a variety of angles for decades. Specifically, since the 1990s, the ubiquitous use of IT in almost any working environment has introduced a shift in work in the "Internet Age" [26]. Although the principles of information processing work were already introduced in manufacturing work much earlier [17], the "transformation of work in a global knowledge economy" [26] was now supported by scientific and technological evidence. Besides a fundamental IT-enabled organizational and institutional restructuring of work in different branches and sectors worldwide, as mentioned by Huws et al. [27], changes in work in its manifold dimensions increasingly attracted the attention of research. In manufacturing, scientific attention basically focused on new qualification and skills requirements, the increase of standardization processes, and polarization processes [25]. Only very few studies dealt with the introduction of machines to improve the working conditions by involving workers in more qualified tasks like programming, maintenance and control [28-33]. There is no single trend in technical development, but there are multiple ones, as pointed out by Krings [34], Sandeberg [35], and van den Besselaar [36]. However, it seemed difficult to reflect on the role of technology in terms of a model of interdependencies related to managerial strategies and to principles of decision-making processes with regard to working environments.

Taking these considerations into account, the paper focuses on the social dimension, which is intimately related to new concepts of complex work environments (CWE). In view of the new HRI, the "social" dimension has to be redefined by reflecting on the interrelationship of robots with humans at work, its organizational models, and underlying managerial strategies. Here, "old" questions discussed in former debates seem helpful, but reflection on the social effects of these technical systems also requires further research and empirical evidence.

Based on different project outcomes ${ }^{2}$, the following Sections reflect on the social dimension of HRI from technical perspectives, pointing to the growing importance of robots worldwide. The authors follow the idea that new technical developments in robotics will lead to a new quality of HRI which will re-define "social" issues of working with robots from a social perspective. This perspective would raise questions as to the involvement of humans, an increase in creativity in work processes, and new forms of quality of work. These reflections are developed in the last Section.

\section{Robots Everywhere}

The dissemination of robots worldwide shows the high relevance of this technology in manufacturing. The introduction rate of advanced robots in manufacturing is still much higher than that of service robots in other branches. However, the expected trend is towards a significant increase in these markets. Most industrial robots (IR) are introduced in the automotive industry, which is the sector with the highest density of robots worldwide [37-39] (see Figure 1).

The average global robot density is about 66 industrial robots installed per 10,000 employees in the manufacturing industry [38]. The high rate of automation in the automotive industry compared to all other sectors is demonstrated by comparison of the number of industrial robots in operation per 10,000 employees in the automotive industry and in all other industries [38]. In international comparison, Japan has the highest robot density in the automotive industry. In 2013, more than 1.5 thousand industrial robots were installed per 10,000 employees in the Japanese automotive industry, while in the other manufacturing sectors the density was 214 robots per 10,000 employees. Considering the automotive sector, this rate is followed by Germany with 1.2 thousand robots, the United States and the Republic of Korea with 1.1 thousand units each. The International Federation of Robotics (IFR)

2 For example the projects Social Implications of Robotics in Manufacturing Industry (IR@MI) at KIT (2012-2015), Intuitive Interaction between Humans and Industrial Robot Systems - A Contribution to a Conceptual Approach (I3RS) at KIT (2012-2015), or the EU project Dynamics of Virtual Work supported by the COST program (2013-2016). Within these projects, the authors conducted several interviews with robotics researchers, managers from the manufacturing industry, technology safety experts, workers' committee members, system developers, and company engineering staff members. 
states that "from 2015 to 2017, robot installations are estimated to increase by $12 \%$ on average per year (CAGR): about $6 \%$ in the Americas as well as in Europe, and about $16 \%$ in Asia/Australia. The trend towards automation continues to increase the volume of robot installations" [38] (p. 17). The strong increase in the number of robots is expected to continue, especially in the Asian market, as shown in Figure 2:

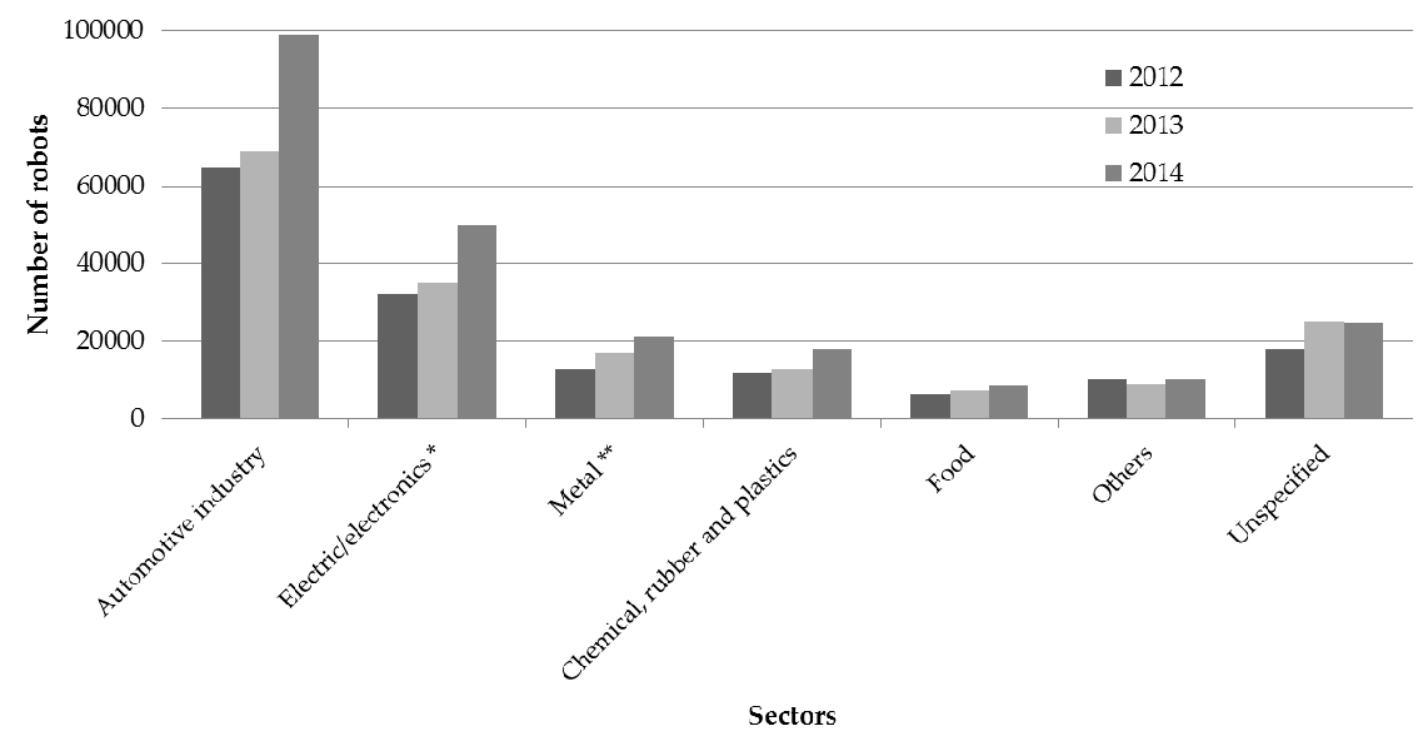

Figure 1. Estimated worldwide annual supply of industrial robots by industries (2012-2014). *: Incl. fabricated metal products, basic metals and machinery industry; ${ }^{* *}$ : Incl. communication, computer and medical precision. Source: World Robotics 2015.

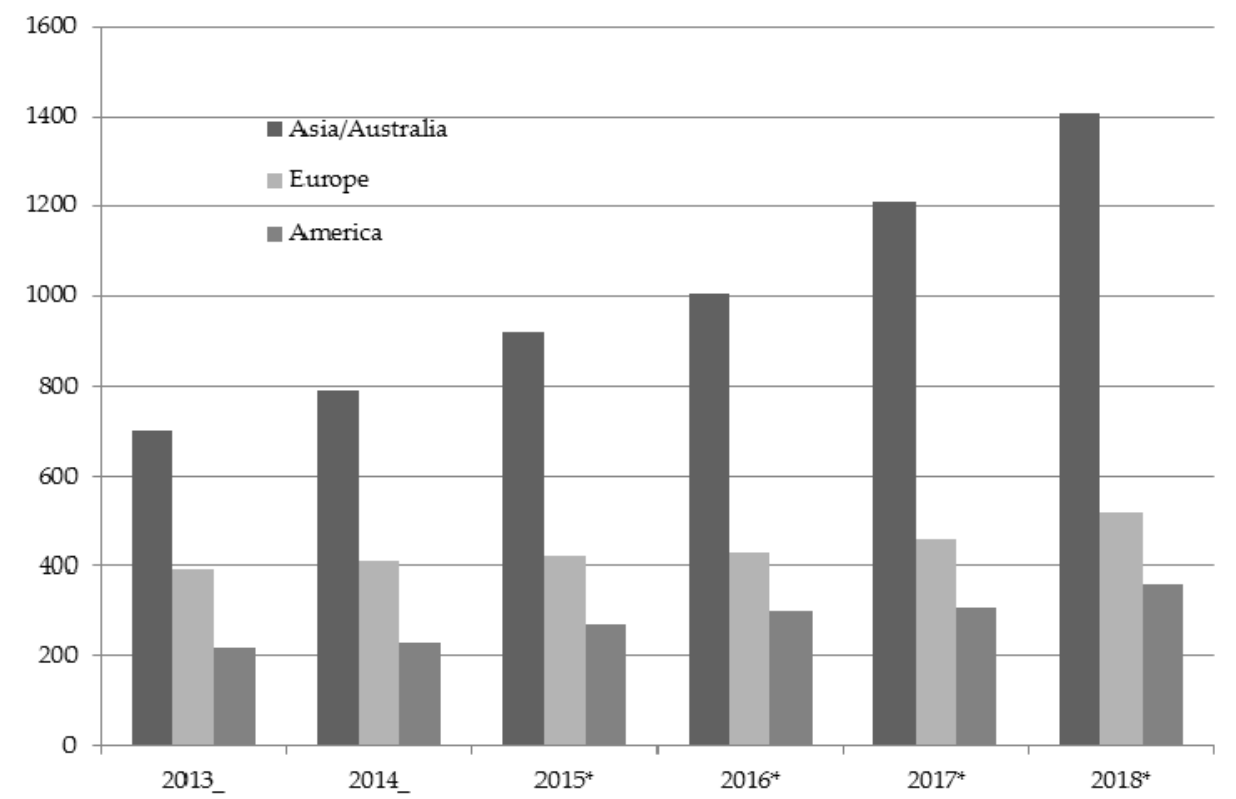

Figure 2. Estimated operation stock of industrial robots 2013-2014 and forecast for 2015-2018.

*: Forecast. Source: World Robotics 2015.

In spite of the financial crisis in most of the large industrial economies, the number of industrial robots (IR) that are still operational is growing fast. That means, the density of industrial robots in the total manufacturing industry can be expected to increase. According to our interviewees, the continued investment in robotics is based on the need to push for increased productivity in companies 
to face competition by reduced lead-to-market time, higher quality standards, and flexible adaptation to the market demand. The products that can be produced at lower cost have been transferred to production sites in regions of the world where price-based competition is intensified. Those products that cannot be produced in that way (because of their technical specificities or quality standards) have been designed to be manufactured in a standard way through automation but still with high variability and quality. Table 1 shows the increase in the density of robots in manufacturing in most industrialized economies.

Table 1. Annual rate of increase in industrial production and density of robots in the manufacturing employment. Source: National Statistics, Laborstat (up to 2008), International Monetary Fund (IMF) and International Federation of Robotics (IFR).

\begin{tabular}{|c|c|c|c|c|c|c|c|}
\hline \multirow[b]{2}{*}{ Year } & \multicolumn{3}{|c|}{$\begin{array}{l}\text { Annual Rate of Increase in } \\
\text { Industrial Production (\%) }\end{array}$} & \multicolumn{3}{|c|}{$\begin{array}{l}\text { Robots Per 10,000 Employees } \\
\text { in Manufacturing (IFR) }\end{array}$} & \multirow[b]{2}{*}{2008 to 2011} \\
\hline & 2000 & 2008 & 2011 & 2000 & 2008 & 2011 & \\
\hline Brazil & 5.7 & 4.9 & 0.3 & $<1$ & 5 & 7 & $40 \%$ \\
\hline China & 11.0 & 13.4 & 13.9 & $<1$ & 10 & 21 & $210 \%$ \\
\hline Germany & 6.6 & 5.2 & 8 & 146 & 236 & 261 & $11 \%$ \\
\hline Japan & 5.8 & 1.3 & -3.5 & 337 & 344 & 339 & $-1 \%$ \\
\hline Korean Rep. & 8.5 & 5.1 & 3.8 & 107 & 221 & 347 & $57 \%$ \\
\hline USA & 5.6 & -1.7 & 4.1 & 52 & 96 & 135 & $41 \%$ \\
\hline
\end{tabular}

As shown in Table 1, the rate of industrial production in China has been continuously increasing in the first decade of the 21st century, with an annual rate of around 13 percent [38], and also other large economies have recovered from the financial crisis. Exceptions are Japan and Korea, where the rate is not that high, but these countries have the highest density of robots in their workforce. What seems striking is the very strong increase in the robot density in the Chinese manufacturing sector of around 210 percent from 2000 until 2011. It should be noted, however, that the robot density is still very low compared to other highly robotized countries (especially Germany, United States, Japan, and Korea) [38].

A major problem of robotization is its potential impact on the industry labor market. Figure 3 shows the high percentage of jobs at risk, based on Frey and Osborne's [24] models of computerization of jobs in the United States.

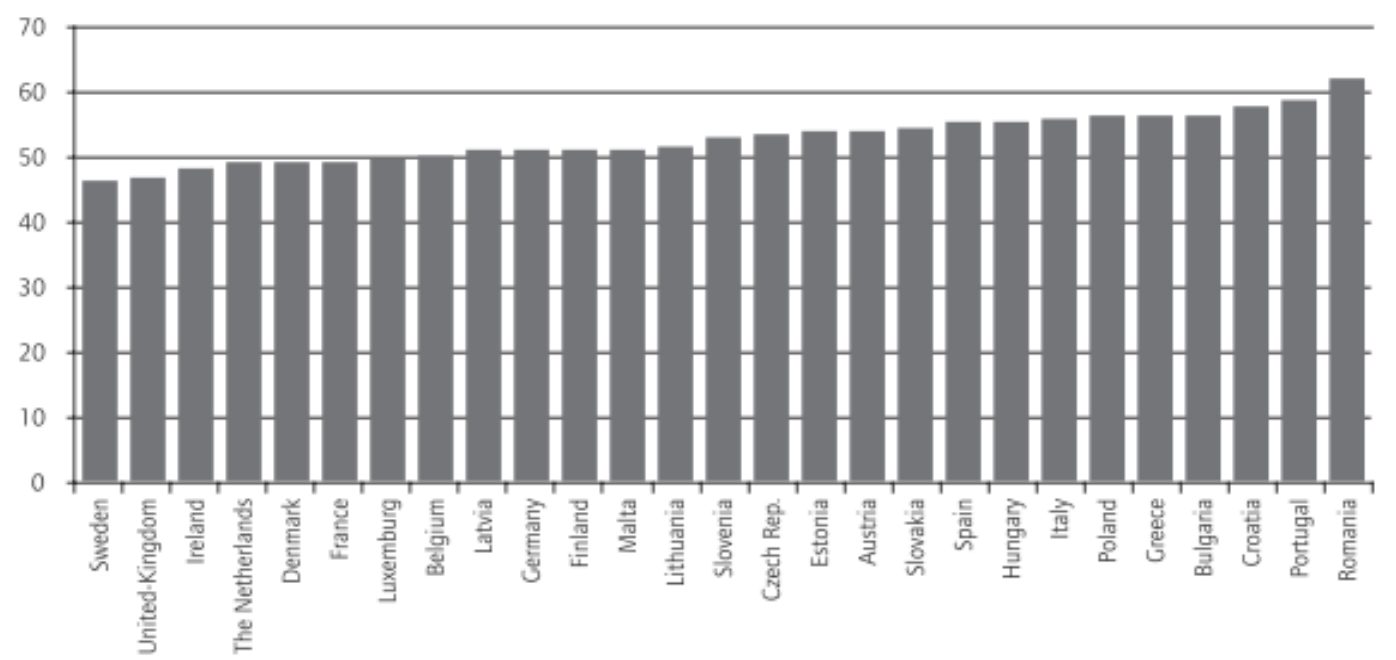

Figure 3. Percentage of EU jobs at risk of computerization by country. Source: Bruegel, calculations based on Frey and Osborne [24], International Labor Office (ILO), EU Labour Force Survey [40]. 
The risks result from the potential decline of employment in manufacturing and the need to increase production volumes, as stated by Gorle and Clive [41] in their report to IFR. Economic pressure on productivity is seen as a significant factor for the increasing investment in robots (and ICT in general) and for labor substitution. Especially those jobs that are characterized by simple and repetitive tasks are at risk to be replaced by automated systems, according to several studies, e.g., by Braverman [17], Corbett [42], Ramioul [43] or Miller and Atkinson [44]. The introduction of robots in manufacturing has been identified as a major trend in the modernization of industry $[1,37,45-47]$. However, the training and skills requirements for operating these machines are much higher compared to conventional tasks. This can lead to shifts in employment. Thus, the percentage of jobs at risk of being replaced by machines is difficult to estimate and other criteria have to be taken into account.

The Organization for Economic Cooperation and Development (OECD) report on the future of productivity by McGowan et al. states that, "labor productivity initially grew rapidly following 1950, reflecting significant scope for catch-up and the rebuilding of war-ravaged capital stocks. Productivity growth decelerated from the early 1970s, but convergence continued in many economies. From the mid-1990s, productivity growth accelerated in the United States, largely reflecting the large productivity gains associated with rapid diffusion in ICT" [48] (p. 21). However, after that, growth slowed down because of the financial crisis in many economies after 2008. Labor productivity in a number of OECD countries had already slowed down before (during the 2000-2007 period). According to the OECD report "the productivity slowdown may partly reflect the pull-back in the pace of KBC (knowledge-based capital) accumulation observed in many OECD economies during the early 2000s" [48] (p. 28). One factor pointed out is the decline in business start-up rates, as observed in many OECD countries even before the crisis. Another important factor is the increasing competition, which impedes the access of small businesses to more advanced technologies. Emphasis is also laid on the fact that "increases in the complexity of technologies over time may have also increased the amount and sophistication of complementary investments required for technological adoption" [48] (p. 49). The OECD report stresses the need for improvements in managerial quality to solve this problem.

To understand the impact of robots in manufacturing, it is important to take into account that this type of production machines is usually applied in large-sized companies. The Fraunhofer Institute of Systems and Innovation Research (ISI) report based on the European Manufacturing Survey states that, "larger companies have more experiences with the introduction of advanced production technologies and more possibilities and higher economies of scale to make efficient use of industrial robot systems" [49] (p. 34). In the same report, Jäger et al. acknowledge that, "manufacturers of rubber and plastic products and manufacturers of transport equipment have the highest share of companies using industrial robots in their production processes, with $46 \%$ and $45 \%$ respectively. This may be basically caused by the large volumes and batch sizes these sectors are able to run in their production processes and in particular in their assembly processes, which allows for intensive investments in advanced automation technologies" [49] (p. 34). "It seems"—-the report continues-"that users of industrial robots are more frequently able to realize higher economies of scale than non-users of robots" [49] (p. 48). In other words, "companies that use industrial robots intensively in their manufacturing operations show a significantly higher labor productivity than companies that do not. It seems that intensive users of industrial robots are better at realizing efficient production processes due to shorter processing times, higher process quality and competitive economies of scale, which enable them to perform manufacturing operations with an above average labor productivity even in high wage countries" [49] (p. 55).

The report by Jäger et al., mentioned above, states that, in case "automation systems and robots enhance human workers instead of replacing them, human-robot interaction has a severe impact on the outcome of the manufacturing industry. The handling of limitations and interdependence of both, technology and human workers is a key issue" [49] (p. 32) and may play an important role in improving productivity and working conditions. The mere replacement of workers by technology will 
not enable long-term improvement of economic indicators, neither at the company level, nor at the national level.

To conclude, it seems that working with robots became reality at least in selected branches like automotive, electronics, metal engineering or plastics already in the last decades of the last century. In these branches, larger companies have developed automation processes to improve their productivity. Such companies are better placed to focus on human involvement in technology processes with new organizational schemes, as indicated, e.g., by Anderson and Gartner [28], Bernstein et al. [29], Brödner and Latniak [50], and Cypher [30]. The more robots are introduced in work environments, the more human interaction with those systems becomes crucial. Thus, a management strategy for human involvement in the production activity becomes decisive for developing and implementing the organizational policy towards productivity or the quality standards adopted. Evaluating the increase in the number of robots in industry without considering its economic impact does not seem adequate. The increase in productivity seems to be the driver for working with robots in many branches.

\section{Robots and New Forms of HRI}

As mentioned before, HRI as a research field has always dealt with safety issues as the basic "social" dimension [51]. In particular, the ISO standard on collaborative robots developed these aspects, such as the ISO/TS 15066. Other standards follow this approach. Most robots operate in industrial settings where they perform different tasks like assembly, welding, painting, or drilling. Evaluation of HRI basically implies a risk assessment in terms of safety. Evidence for this can be found in the EN ISO 10218-1:2006 standard on safety requirements for robots for industrial environments, published in 2006 [51-53]. As pointed out by Fischer and Lehrl [19], Frey and Osborne [24] and Wagner et al. [54], this standard refers not only to the ergonomic dimension, but also clearly emphasizes organizational issues (social implications) where different options are available, such as the question whether workers should perform more qualitative tasks or should be integrated in work group concepts.

Robotic assistance to enhance the manual dexterity and accuracy of instrument manipulation is mainly used in the manufacturing industry, as stated by Dario [55] and IFR in general [38]. This can be illustrated with the example of the light-weight robot developed at the DLR Institute of Robotics and Mechatronics: "Sensor technology, like the integrated joint torque sensors and link side potentiometers in addition to the common motor position sensors, allow for the implementation of safety features which go far beyond the state of the art in industrial robotics and facilitate the opening of new markets like medical applications or future service robotics scenarios. Potential industrial application fields are the fast automatic assembly, as well as manufacturing activities performed in cooperation with humans (industrial robot assistant)" [56] (p. 10). With regard to robot assistants or collaborative robots in industrial environments as described in Albu-Schäffer et al. [56] (see also Kaiser [57], Kochan [58], and Krüger et al. [59]), the studies by Kobayashi et al. [60] and Medeiros and Sadowski [61] refer to the importance of further research on the integration of humans in robot systems.

With new technical developments that may create a new quality of working environments, HRI research is facing great challenges today. The most relevant issues are:

(a) augmented reality, haptics and human enhancement

(b) task complexity

(c) intuitive interfaces

\subsection{Augmented Reality, Haptics, Human Enhancement}

The "augmented reality" (AR) approach seems to allow for new working methods, basically related to simulation tasks in many working environments. To date, most applications are in the medical sector and manufacturing industry. In the near future, it will be possible to use it in most branches, from tourism to logistics. Augmented reality implies artificial vision and human-machine interfaces with complex layers of artificial intelligence that enable the anticipation of work actions and 
connection to relational and knowledge-based systems. Here, the interaction is based on innovative visual markings. AR allows programming, e.g., an automatic surface fitting with constant contact force. The augmented reality approach, as one form of assisted technology, also provides major opportunities for HRI in safer environments. Furthermore, it can be used in telerobotics because it allows the operator to work as if he was present at a remote work environment. According to Nee et al., virtual reality has been proven to be useful in medical robots for surgeries and telerobotics and "some studies have reported the use of AR in robotic systems to address HRI and robot programming issues" [62] (p. 664). Augment reality can also provide a means for visual feedback to the robot operator [56]. Nee et al. conclude that, "the use of virtual robot models enables the operators to program the robot by guiding the virtual models without having to interact physically with the real robot manipulators" [62] (p. 664).

As Kaiser [57] mentions, robots should provide the capability to autonomously execute certain operations and relieve the operator in manufacturing environments from difficult control tasks. According to Kaiser, "robot skills" means the ability of the robot to safely change something from a current state to a desired one (from the programmer's point of view) in the presence of uncertainty, "with the individual control functions applied using only initialization data and direct sensorial information at runtime" [57]. It is stressed that it is most important that the access to the necessary information is as easy and intuitive as possible [63-65]. According to Prewett et al., "the literature highlights the importance of the visual channel in determining HRI task performance" [13] (p. 846). In the same paper, the authors identify three main pieces of evidence from several studies:

(1) Users have better functioning in visually sparse or simple environments.

(2) Studies that manipulated visual features to mitigate workload report a positive impact from the interventions.

(3) As task demands are increased, auditory and tactile feedback facilitates operator's work [13] (p. 846).

One important conclusion from these studies is that augmented reality and haptics will play an important role in the development of HRI offering better working conditions. They can eventually become a condition for task performance. In near future the operator will become enhanced with assistive components that will enable him/her to increase the awareness at the working place and the performance of his/her tasks.

According to Tsarouchi et al., "[r]egarding the physical HRI and safety, numerous research studies have been done so far. Despite the fact that these aspects are really important to HRI in an industrial environment, there is no considerable research directed to such applications" [66].

Such approaches are even more important whenever "dependability of complex robotic systems in anthropic domains during normal operation is threatened by different kinds of potential failures or unmodeled aspects in sensors, control/actuation systems, and software architecture, which may result in undesirable behaviours", as stated by de Santis et al. [7].

\subsection{Task Complexity}

Without doubt, working with robots implies a higher level of task complexity. This complexity is increased by interfaces with ICT and robots, multitasking, responsibility for machine operation, anticipation of robot action, and decisional procedures. Interference effects with human actions and management of potentially conflicting work areas [14,42,67-69] as well as the definition of principles to regulate the involvement of humans in the control of such equipment as system agents are other aspects that can further contribute to the task complexity. With an increase in the number and complexity of such interfaces, the capacity of human intervention can become limited and further problems may arise, even with unmanned systems [70]. For example, the variety of inputs may decrease the awareness for prevention of potential problems or situation awareness. Attention may be focused on interface elements that are less complex, while de-focused attention may cause a perception problem, especially 
if the interfaces require particular attention or are quite complex in its components as mentioned by Colombo et al. [71], Lenz [72] and Morioka and Sakakibara [73].

Some research questions can be described as dealing with concepts of the relation of automated systems and job design. At first glance, it may seem that they have been recurring issues over the last years. However, an evaluation of these concepts seems difficult. A common hypothesis in the literature is that working with robots has significantly increased safety problems in production areas. Another problem identified is a shift in the framework of the relation between humans and machines in their work environment. New questions should be asked to understand emerging problems of allocating, monitoring and diagnosing responsibilities in automated systems due to increasing task complexity $[14,30,74,75]$. For example, Tsarouchi et al. state that one important challenge for HRI "is the design and development of multimodal communication frameworks that aspire to simplify the programming process of complex tasks" [66]. These problems depend on the management policy of work organization, on the cultural context of the company, on the competence and experience of the workforce.

In such conditions, it can be questionable how far it is possible to implement real interactive procedures. The same applies to the use of HRI including organizational dimensions. We cannot really speak about "common aims" in co-working environments that integrate humans and robots. However, the concept of "common aims" must be seriously taken into account when developing workgroup strategies $[16,58,74]$. And is it possible at all to design such work environments without appropriate workgroup strategies?

Given the expected trends of robots in manufacturing, it is also necessary to discuss the role of agents in complex work environments (CWEs), including robots, automated machinery, sensors, and human operators with increased task complexity and mental workload $[7,45,76,77]$. This discussion refers to the inner logic of technological development in each element involved in the working environment, and to their implications for the way humans work as and use such agents in their work environment $[28,30,56]$. This requires explicit definition of different decision-making processes with regard to different models of working environments and work quality in such CWEs, following Eason [78], Groom [79], and Moniz and Krings [10]. Generally, this type of analysis continues to ask: What is an autonomous system in the production sphere? And who is the end-user with individual responsibility and capacity for decision-making in operating processes that may affect safety and quality of work? The answers are manifold and provide a better understanding of the role of human work in increasingly automated spaces $[5,7,46,80]$.

In the epistemological tradition of "social construction of technology" from Bijker et al. [16], Huws et al. [26], or Wagner et al. [54], technology can be defined not as a tool or an equipment designed and marketed, but as a socio-technical relation that integrates the equipment and working tools, the operators, and the material to be transformed. In these relations, the concepts of "agents", "co-working" or "human-centered technical systems" constitute new working dimensions related to HRI. Agents in work spheres and co-working action also lead to greater complexity of work environments.

\subsection{Intuitive Interfaces}

As shown above, new technical requisites are to be actually found in industry: "[...] being easily combined with manual labor in a safe and natural way, without adding safeguards and interlocks that increase engineering and installation effort beyond economic viability", as stated by Kock et al. [81].

Most of them are being developed in the field of applied artificial intelligence, such as augmented reality and artificial vision with regard to manufacturing tasks. Intuitive interaction is another issue that may play a role in improving these human sensing capacities using new technical innovations. This view is widely confirmed by many robot manufacturers using this approach in their research and development activities [53,57,65,82,83].

Widening the perspective to identified social implications such as intuitive interaction between humans and robot systems is the central motivation of this hypothesis. In this context, different 
technical options of intuitive interaction have to be analyzed and assessed, for example, with regard to increasing decision options for human operators. However, intuitive HRI is also able to increase technical autonomy (autonomous robots or agents in complex systems) and displace human labor. In other cases, intuitive HRI can enhance safety, increase productivity, and facilitate human operation in working environments. Finally, highly qualified work environments with robots usually require more sophisticated systems for co-working strategies [7,13,52,84].

Studies on HRI, e.g., by Thrun [12], Bernstein et al. [29], Schraft and Meyer [83], Kiesler and Hinds [68], or Hinds et al. [77], also stress the significance of intuitive interfaces in the interaction between humans and automated systems. Some of them underline that, in a few years, human-robot interaction will become a primary concern in the majority of robotic applications. Barattini et al. discuss the recognition of "gestabulary" (gesture vocabulary) or "feedbackulary" (feedback vocabulary) [45] as sets of standard gestures or feedback for specific commands. Others point to the need to develop intuitive teaching methods to be applied in small and medium-sized enterprises [83]. At least there seems to be consensus across the scientific community that many of the current problems in HRI are yet to be solved. And most of those contributions would come from different scientific backgrounds, as social sciences to be one of them.

Some authors still argue that intuitive programming of robots, i.e., Programming by Demonstration, is needed to transfer human skills to the robot, as is mentioned by Colombo et al. [71]. However, the aim should not be to leave the human operator without skills but to develop methods that allow human operators (or tutors) to "teach" simple tasks to robots, and not "transfer" them.

Mohs et al. define intuitivity as the existence of unconscious application of prior knowledge that leads to effective interaction [65] between humans and robots. We may also apply this definition to HRI. The question remains whether the dominant model of work organization with HRI enables and recognizes the role of tacit knowledge in work processes. In the intuitive interaction process, the decision-making process usually includes a tutor-a robot operator or a software programmer-depending on the organizational options. However, the robot system as an autonomous agent is also included in the decision process. According to Kaiser, the effort involved in control design can only be effectively reduced when a decision is subject to mutual confirmation by a human operator and an automated agent (e.g., a robot) [57]. For Heyer, the question is "how robots fit into existing organizational structures, and how they are accountable to the organization in terms of safe and reliable operation is yet to be determined" [9]. Such statements demonstrate that in most modelings of robots, actions between humans and machines need to be defined as a socio-technical relationship.

The relevance of human/operator-robot interfaces (HMI in general, and WRI in particular) is due to complex work systems using robotic system at the shop floor. Therefore, in HRI research there must be a stronger focus on social aspects of working, such as those related to the emergence of new competences, skills and new training needs, as well as to productivity and improved workplace environment [85-87]. These topics were very important in the debate in industrial sociology during the last decades of the 20th century and are also relevant in the context of robotic work environments. The discussion about the social implications of automation in manufacturing can also serve as a starting point to discuss the present conditions of HRI development and possibilities for its implementation at the shop floor.

Such perspectives to HRI have been conducted using interdisciplinary analysis methods, joining social scientists and computer scientists. The studies on technology assessment and work developed by the authors at ITAS-KIT (see $[84,88]$ ) use the method of interdisciplinary analysis to analyze existing approaches to HRI. The involvement of social scientists and computer scientists in common research on work and technology can contribute to a holistic perspective of the problems related to the integration of humans in automated environments (CWE) or to working with robots, and can help identify solutions for improving working conditions. This methodology aims to improve the knowledge awareness about the use of intelligent robots at the shop-floor level in the manufacturing industry. 
It also aims to evaluate the available organizational alternatives of using intuitive robot interaction to improve performance and productivity outputs.

Preliminary results confirm the assumed positive correlation between participatory approaches of intuitive robot interaction and performance output. In fact, industrial automation is achieving more advanced capacities that contributes to improved production processes in terms of higher performance levels, better quality standards, and increased technical flexibility. The complexity and flexibility of manufacturing equipment is revealed, in particular, by the need of programming or re-programming (off- or on-line) options and by increased multi-functionality. For instance, new programming methods allow the automated production of small lot sizes or even single work pieces, hand drawings made with a digital pen can be automatically transferred into robot programs, or robot trajectories can be defined by guiding the robot using tactile feedback. Such flexibility can improve task performance, with direct effects on quality, safety, and productivity [28,74]. These technical possibilities can justify the adoption of some models of tasks organization that give more autonomy to workers and improve communication flows between different working groups and technical staff. Increased flexibility may also enable better involvement of system operators in decision about better options.

Safety is not a new problem, and although much research has been done recently in this field, it is still unsolved. The aspect of safety in manufacturing automation should also be considered from the social perspective. Other aspects that are closely related to the social dimension deal with ergonomic design, situation awareness, risk assessment, and quality of working life. Thus, the overarching research topic clearly refers to the "social implications of robotics", which was defined by Tranfield [89], Eason [78], and Das and Jayaram [67].

\section{Social Aspects of HRI: New Concepts?}

Some of the most critical approaches to the development of robots in industry raise the question whether their use may lead to labor displacement or replacement, as stated by Corbett [42], Krings [88] and Ramioul [43]. Will job profiles improve if robots take over dangerous, dull and dirty jobs, as promised for the adoption of these technical changes in thousands of manufacturing companies around the globe? To answer this question, it is necessary to know if the use of robots may lead to an extension of the digital divide between those that have higher qualification and can get involved in the decision-making process, and those that are supposed to be only passively involved in the technical system. Empirical evidence shows both sides of the medal. Usually, highly qualified workers can be expected to have better chances to deal with robots and CWEs. Less skilled workers, however, are likely to get involved in workplaces that are poorer in content and imply repetitive and simpler tasks, also working with automated systems but without any further action besides "pushing buttons". While robot manufacturers usually develop their systems considering the job needs of a system programmer or an ICT expert, the perspective of the operator in the loop is often neglected. This perspective should form the basis of the WRI concept, and to a certain extent, a generalized HRI concept.

In fact, these issues have been discussed in social sciences for several decades. The trends show that the "classic" questions with regard to qualification and skills, shifts in work, and substitution of work are still crucial in reflecting on new technologies. This is specifically true when it comes to the interlinkage of manufacturing in global value chains. However, the most recent developments in robotics demonstrate the need to revise the concepts discussed. When reframing and reflecting on new questions, it seems important to increase collaboration among social scientists, engineering scientists, and computer scientists, following Fischer and Lehrl [19], Gorle and Clive [41], and van Est and Kroos [1]. Knowledge from other disciplines can provide an important reference framework when social scientists analyze and debate organizational alternatives and the availability of choices with regard to HMI. We may extend these debates to the application of robots. Without doubt, collaborative robots and new technical issues like augmented vision in manufacturing raise new questions and challenges, because they offer new elements to consider with regard to the design of workplaces and 
organizational models. In all, such issues always imply the need for further qualification and new competences among the workforce.

There are several empirical studies on HRI or CWEs, or just on human interaction with automated systems $[31,60,79,90]$. What seems new in these studies is the call for considering the ethical and legal dimensions of technology, which, however, very often does not seem to be related to the organizational framework of the specific contexts. The legal dimension basically refers to safety issues, whereas the ethical dimension is strongly related to issues of working with robots [1]. The regulation framework does not approach the issues of job substitution. The technical assessments raise ethical questions without considering the expectations and needs of the human workers. Focusing on human involvement strategies in technology innovation in organizations becomes crucial to understand the implications of the use of those technologies. In that sense, do they improve productivity? Do they generate new organizational configurations? Or can they improve the quality of work environments?

New approaches to a new quality of HRI, however, include participatory strategies that still have to be developed. Robotics application in work environments requires consideration of new issues of the design of tasks, compliance of machine integration in working groups, and increasing complexity of data processing. Such workplace design must take account of the integration of multiple interfaces that require more interaction of humans with sensors, robots and buffers, as well as different competences and responsibilities. Vice versa, these new functions may also allow for new forms of human influence and creativity in working processes.

As mentioned above, new workplace design goes beyond merely ergonomic issues. It also includes software tools to be used by workers. These tools include knowledge-based systems, augmented reality, and communication processes. Therefore, research on the development of software to integrate knowledge-based systems into automated and programmable machinery is also an empirical field, where the field of tacit knowledge can raise new problems of formalized knowledge. Several sociological studies already addressed these topics, but almost no research was done in the context of complex manufacturing systems [10,12].

In some cases, teleoperation is increasingly used in applications that are dangerous for humans. However, these applications are not totally autonomous and usually cannot be operated without any control by humans. It is therefore important to understand that HRI can also take place in teleoperation systems. This is perhaps most evident in surgery.

Everywhere, the number of robotic applications is increasing in sectors where there was little or no automation before. Applications in agriculture, healthcare or surgery reveal the potentials and challenges of the use of robots in all working spheres-not only in manufacturing. New studies on the assessment of attitudes towards robots or the use of robots and the workload in HRI provide further empirical evidence on co-working concepts $[7,9,55,77]$ and show the potential of robots working side-by-side with human operators.

Some of these new concepts of HRI are related to language processing. The use of natural language for programming is particularly relevant in the fields of manufacturing and professional use of robotics. New applications of augmented reality can include the increased use of social robots (or cobots) featuring natural language and knowledge-based processing. The use of natural language can also have great importance in teleoperation. A new challenge lies in the cultural environments of robot applications. In such technical configurations, the socio-technical approach is increasingly important to HRI in work spheres. Haptics is not very relevant in manufacturing, but with the introduction of augmented reality new problems will arise, such as the required immersion of the operator in a simulated environment or the possible lack of experience in using artificial vision devices. This field is particularly relevant to safety issues [46,75]. Attention, mental workload, stress, trust have to be dealt with in a balanced and participatory manner in order to avoid dysfunctional problems and accidents.

Research on intuitive robot programming in manufacturing has already been conducted for 25 years (see Heise [14], Cypher [30], Münch et al. [91], and Kaiser [57]). In recent years, intuitive programming and the intuitive "use" of technology has become relevant in a variety of processes 
in industry. The intuitive use of technology has also increasingly been applied to ICT products, as mentioned by Colombo et al. [71] and Rogalla et al. [92]. Furthermore, it is required in the development of complex equipment and machinery [29], such as computerized numerical control (CNC) machine tools, flexible manufacturing systems, and industrial robotics as refer Marin et al. [93] and Prassler [53]. The development of programming procedures in those industrial machines in the last years was aimed at providing machines with a simpler software language or even intuitive representations, and has made it possible for most workers to operate machines with more complicated features and capacities then before. Automated system manufacturers have already reached very high levels of technology development, but there are still some steps to take in simplifying their use and making it more intuitive and simple. All these approaches have raised new problems as to how people interact with equipment and machinery. Following this rationale, a challenge has been the modeling of work organization under such conditions. Managers and analysts used to consider work organization modeling in a classical way, based on conventional or even conservative models. But with the implementation of those technologies, and more generally with the increase in CWEs, alternative designs of work organization are needed. Hierarchies, centralized decision processes, authority, and traditional control are concepts that should be re-evaluated under these new conditions. To a certain extent, the development of autonomous systems (AS) and the widespread use of HRI in manufacturing have brought new models of work organization, task distribution, work content, organization of working times, taking into account aspects of safety, maintenance, control, and feedback. When considering these issues, the "social" dimension should be defined with regard to new technical problems.

There are various limitations and challenges to the development of approaches to intuitive HRI. Many efforts have been made recently to enable easy and intuitive interaction with robots that would need more software developments. Applications that integrate the concept of the Internet of Things (IoT) are being increasingly introduced in the shop floor environment. The same applies to augmented reality and haptic developments. Experiences in the field of social robotics can demonstrate that $[79,94]$. However, there are still relatively few examples of the use of HRI in work environments, as shown by Lenz [52] if we consider all working places around the world. It has, however, a growing interest in the manufacturing industry, but the existing cases are still limited. The aspects of workgroup concepts, participation in decision making, de-centralized decision processes, feedback, and work autonomy must receive adequate consideration in any approach to HRI based on intuition and knowledge-based resources. These approaches should focus on improving the working environment, as well as the decision-making and control processes, in order to provide for safer workplaces and increased productivity. Further knowledge of these social dimensions is needed to develop appropriate tools and systems for human-robot interaction.

Several HRI studies have pointed out the psychological aspects related with tensions on the use of ICT systems in work spheres $[64,80,83]$. To a certain extent, the outcomes of these studies may be also applied to our perspective. For example, the above-mentioned concept of human-centered technical systems should not only be defined based on the technical configuration of a system, but more in terms of the organizational configuration, because this concept of CWE leads to new patterns of HRI and, more specifically, WRI $[14,75,76]$. In other words, in CWEs, workgroup concepts (such as flat hierarchies and decentralized decision processes), as a specific type of organizational configuration, require higher technological expertise among the expected competence of the workers. In a WRI environment, an operator should have the capacity to decide and intervene autonomously when a potential problem may occur in order to ensure smooth operation of the system and achieve higher productivity levels in terms of time to delivery and product quality.

A recent European project (SMErobot) has developed these tools. The reconfigurability and modularity of the control system have been exploited in order to implement Programming by Demonstration based on manual guidance and in order to use a low-cost programming device developed by Colombo et al. [71]. In recent years, the collaborative robot manufacturers have continued on this path. They propose to extend the control architecture with the objective to have a robust and 
interactive robot control, where the "target is to have an intelligent controller, safe and robust, able to understand complex tasks and to share them in simplex commands" [71]. These aspects are important elements of the intuitive interaction concept.

To summarize, observations show that robotic systems do not necessarily determine the model of work organization to be adopted. There are different options of organizing HRI environments. But robot manufacturers are aware that most forms of organization limit their options in terms of the re-configurability of automation systems. In interviews conducted by the authors, experts point to the possibility of determining the way production systems are used. That is, when implementing robotic systems, the decision between several organizational options is taken before a technical system is adopted. In many cases, however, the adoption of new technical systems can limit the development of organizational models. This often results in a difficult and sometimes conflictual process of adjustment.

In this context, issues of the design of new interfaces and the principles of decision-making in organizations arise. Most examples can be found in the manufacturing sector, but also shows more and more organizational shifts by these technologies, where the processes of communication are defining principles of decision flows. The definition of work organization implies the definition of tasks to be accomplished by humans with more or less autonomy, using tools and intelligent equipment. Approaches to HRI should therefore be closely linked to approaches to organization models in industrial work systems. Due to the mutual relationship between humans and machines, the implementation of robots is a process that has important implications: Does information and communication become more formalized and the process becomes standardized or vice versa? Does it increase (or reduce) human creativity and the influence within HRI? Or that formalization happens just with robots and with HRI and not with the other agents in the working process? There are two major alternatives, depending on the chosen organizational model of work environments. In some (few) cases, highly qualified human operators can intervene in the production process and control it from a higher level of action. In other cases, low-skill operation only allows the process to be monitored; due to the few interaction possibilities, the human workplaces can become irrelevant. The different outcomes depend on the choice for a specific model of work organization $[25,35,77,95]$.

\section{Concluding Remarks: Humans Working with Robots}

The development of a highly advanced manufacturing industry in Europe based on robotic systems is a clear political objective. In order to achieve higher productivity levels, companies should provide conditions for highly skilled workers to improve their working capacities and resources by using robotic systems, which allow for higher levels of competence and quality as well as simple, precise and intuitive modes of interaction. As highlighted in this article, new technical options offer new modes of HRI.

Technological developments in the manufacturing industry receive new input from research in sectors such as services, logistics or health. Automation models from manufacturing, on the other hand, are transferred to other sectors (food production, agriculture, health, and mining). In general, it can be said that industrial organization models are also applied to services. Research questions should therefore be considered in the respective work contexts. Here, it is interesting to know what kind of research and development has been done on the integration of robot systems in complex work organization models. Most manufacturing companies using several types of CNC machine tools, conveyors, automated warehouses, sensors and robots have specific problems of interaction to cope with. The systems of communication between the equipment units always present operational problems, but the integration of humans in such systems is particularly difficult. System integrators usually do not reflect on and develop socio-technical concepts of working environments. At most, they seem to consider the adaptation of humans to the machines: human operators need to have appropriate conditions to perform their tasks (training, experience, and skills as well as additional social competences to be integrated into working teams and to perform their tasks in the automated environment. 
Concepts of learning processes, competence building, decentralized decision making, and participative organization models are particularly relevant in manufacturing environments with increased automation systems and advanced HMI. In order to develop "social" categories of HMI, there must be a mutual relationship between humans and robotic systems. An advanced concept of work organization that improves the development of competences, decision making and task enrichment systems could lead to better working conditions and a higher quality of work life.

Programming of industrial robots is still very time-consuming and requires experienced personnel. For many tasks - especially in small and medium-sized enterprises and with small lot sizes-this effort does not pay, as pointed out by Eason [78], Ribeiro and Barata [96], Schraft and Meyer [83], and Ritter et al. [33]. Intuitive interaction can reduce the amount of effort and increase the accuracy of programming and planning.

New conceptual approaches to the interaction of humans with industrial robots do not only consider technical aspects but also raise questions such as:

(a) Considering that HRI is not a merely technical approach, do they also offer possibilities with regard to improve working conditions in industry?

(b) How far are the approaches to designing intuitive robot interfaces related to new concepts of HRI?

(c) Are image schemes and their metaphorical extensions useful for user interface design?

(d) Is the human-robot interaction characterized by a relationship of trust? In other words, How far do humans trust in robots in work environments?

When answering these questions it is important to bear in mind that robot users are usually skilled workers trained to perform their manufacturing tasks or specific robot operations. An OECD report states, "skills can be gained beyond formal qualifications through both on the job-training and opportunities for lifelong education and training, which may also raise labor productivity via lower mismatch" [48] (p.66). Developing new work practices, internally reallocating over-skilled workers, or retraining low-skilled workers are core practices of a managerial quality principle in companies. Taking these practices into account, HRI may also lead to more creative input from operators and increase the quality of work.

Depending on the model of work organization, workers can either be involved in decision-making, proceed some programming fine tuning, apply quality control procedures and develop basic maintenance tasks, or carry out only standard procedures of surveillance and basic operations. In the first case they should have higher training on robot operation; in the second case they require only basic training procedures.

In the case of industrial robots, they are usually operated by qualified workers of the manufacturing sector. However, if the robots are used for repetitive and simple tasks usually it displaces low skilled workers who become controllers of the system, are dismissed or assigned to other areas of the shop floor. If robots are used in complex tasks in order to relieve workload and physical stress, the human operators must improve their skills and increase their competences by continuing allocated to the workplace. In such cases they can even use their tacit knowledge improving the quality of work environment. They must take on new tasks associated to the operation of the robots, such as maintenance, programming, data management etc., which sometimes involve increased responsibility.

In the manufacturing industry, it seems important to know what the criteria in place for new programming are. And also one must know which new operation concepts can be developed at the computer integrated working cells that associate robots, AGV, CNC machine tools and other automation elements. Such knowledge is a condition for a better-designed workplace with CWE. In industrial sociology research on robotization in manufacturing, a focus has been on gaining knowledge about the social competences and skills required of robot operators. Most studies have identified several distinct organization models that use the skills requirements differently. The occupational competence can be developed accordingly to those different options. The models used are often strongly related to management strategies for improving competitiveness and performance. 
Another question is how far tacit knowledge at the shop floor can be articulated for intuitive robot operation and control. That can need also a knowledge codification for such operation mode. To answer such questions, an interdisciplinary approach involving socio-psychology and computer sciences is needed. Both perspectives can contribute to facilitating the use of workers' competences and professional experience in order to improve automation processes.

When developing and designing the intuitive interfaces for industrial robots, such as hardware, software and system integration, robot experts in the manufacturing industry usually do not clearly recognize the "social" implications of their concepts. The relation between intuitive design, and the possibility to enable and improve the qualification of workers operating the equipment is still large unknown. In other words, does intuitive design enable less skilled workers to perform the necessary operating tasks or does it require higher qualified operators? And what are the implications in terms of safety? Does intuitive interfaces enable better production safety? Are there qualification conditions?

Assessing the alternative options is important to ensure an informed decision-making process. This requires interdisciplinary knowledge and collaborative research. But do existing approaches in social sciences (sociology, psychology, economics, political science, anthropology) provide meaningful input here? A literature research [78] has revealed that the number of papers using this approach is limited, at least when compared to similar studies on ergonomic and working conditions. Therefore, further empirical evidence is needed in order to contribute to the conceptual development in this field.

Dario et al. stated already in 1996 that "most of these problems are new for the robotics researchers, used to deal in the past with robots which operate in strictly controlled environments (like industrial robots) and/or conditions (like, for example, robots for space, or for submarine or nuclear applications). However, it is important to observe that many of the problems posed by the interaction between human and robots in different environments (for example when the robot must "live" in a place, like a house, where a human being lives) are quite familiar to other research communities. Psychology, anthropology, social science and industrial design are some of the areas with which the robotics community will be 'forced' to collaborate increasingly in the future. It is our opinion, however, that these collaborations will further fertilize with stimulating and intriguing new ideas in interdisciplinary fields of robotics" [55]. Some decades later, this continues to be a scientific challenge, and a systematic research approach is still lacking.

The development of totally autonomous systems should not be considered a primary goal. Usually they are only developed for simple and repetitive tasks. For more complex tasks, the aim should not be to replace skilled work, but to assistance human workers. Technical solutions should also integrate social and ethical issues. Strategies for technology development in this field are thus placed in a totally different context. This means that humans should be at the heart of production developments, with machinery (including robotics) used as supportive or assistive systems.

Robotic systems in manufacturing raise the problem of how to integrate the organization of complex tasks with several workers in different workstations. The probability that an existing production model will continue to be used after the introduction of robots is very high. System developers usually only provide technical solutions to the companies, but no organizational ones. However, the interaction between workers and robots requires organizational solutions, mostly in terms of increased complexity of decision-making. From this perspective, new forms of work organization in manufacturing, such as task enrichment, job rotation, and semi-autonomous workgroups, should be considered in the HRI design. Furthermore, the most conservative solutions (one machine for one workplace) bring additional problems of rigidity, increased number of failures (sometimes involving safety issues), or unexpected results.

The analysis of HRI in the manufacturing sector requires further micro-level empirical evidence. Social science studies on workplace changes can be used as benchmarks for increasing quality standards and improving market sustainability. However, a further step should be taken. Social scientists should collaborate with system developers to jointly search for new solutions that integrate organizational factor in order to identify and integrate the social dimensions in new HRI strategies in industry. 
These "social" dimensions should include the quality of work in manufacturing, addressing "old" questions in new ways.

The number of studies on HRI has increased in recent years, and the debate on intuitive interaction demonstrates the high interest in the field. The robot manufacturing industry has become increasingly involved in such research activities, while in product development further attention must be paid to safety issues. However, the higher the need for safe automation solutions, the higher the intensity of applied research on ergonomics and working condition studies.

It is obvious that there are several limitations and challenges to the development of HRI approaches. These should be tackled with the aim of improving the working environment as well as the decision-making and control processes, which are needed to create safer workplaces and to achieve improved productive outcomes.

Acknowledgments: The authors have received support from the projects "Intuitive interaction between humans and industrial robot systems" (I3RS), "Social implications of robotics in manufacturing industry" (IR@MI) at KIT and "Work and Technology" at ITAS to this research work. These projects also contributed to cover the costs to publish in open access.

Author Contributions: António Moniz and Bettina-Johanna Krings conceived and designed the experiments, performed the experiments, analyzed the data, contributed reagents/materials/analysis tools, and wrote the paper. Both authors have read and approved the final manuscript.

Conflicts of Interest: The authors declare no conflict of interest.

\section{Abbreviations}

The following abbreviations are used in this manuscript:

$\begin{array}{ll}\text { AGV } & \text { auto-guided vehicle } \\ \text { AS } & \text { autonomous systems } \\ \text { CICS.NOVA } & \text { Interdisciplinary Centre of Social Sciences } \\ \text { CIMS } & \text { complex integrated manufacturing system } \\ \text { CNC } & \begin{array}{l}\text { computerized numerical control } \\ \text { complex work environments }\end{array} \\ \text { CWS } & \text { complex working system } \\ \text { FCT-UNL } & \text { Faculdade de Ciências e Tecnologia [Faculty of Sciences and Technology]_Universidade } \\ \text { HMI } & \text { Nova de Lisboa } \\ \text { HRI } & \text { Human-machine interaction } \\ \text { ICT } & \text { information and communication technology } \\ \text { IFR } & \text { International Federation of Robotics } \\ \text { ILO } & \text { International Labor Office } \\ \text { IMF } & \text { International Monetary Fund } \\ \text { IoT } & \text { Internet of Things } \\ \text { IR } & \text { industrial robot } \\ \text { ISO } & \text { International Standard Organization } \\ \text { ITAS } & \text { Institute for Technology Assessment and Systems Analysis } \\ \text { KIT } & \text { Karlsruhe Institute of Technology } \\ \text { OECD } & \text { Organizational for Economic Cooperation and Development } \\ \text { OTA } & \text { Office for Technology Assessment } \\ \text { SR } & \text { service robot } \\ \text { WRI } & \text { worker-robot interaction }\end{array}$

\section{References}

1. Van Est, R., Kools, L., Eds.; Working on the Robot Society; Rathenau Instituut: The Hague, The Netherlands, 2015.

2. Kelly, G. The robots are coming. Will they bring wealth or a divided society? Available online: https://www. theguardian.com/technology/2014/jan/04/robots-future-society-drones (accessed on 12 July 2016).

3. New York Times. Cheaper Robots, Fewer Workers. Available online: http://www.nytimes.com/2015/04/ 25/technology/robotica-cheaper-robots-fewer-workers.html (accessed on 29 July 2016).

4. New York Times: Bits Robotica series. Available online: http://www.nytimes.com/video/robotica (accessed on 12 July 2016). 
5. Ejiri, M. Towards meaningful robotics for the future: Are we headed in the right direction? Robot. Auton. Syst. 1996, 18, 1-5. [CrossRef]

6. Jasanoff, S., Ed.; States of Knowledge: The Co-Production of Science and Social Order; Routledge: Abingdon, VA, USA, 2006.

7. De Santis, A.; Siciliano, B.; De Luca, A.; Bicchi, A. An atlas of physical human-robot interaction. Mech. Mach. Theory 2008, 43, 253-270. [CrossRef]

8. Hartwig, M.; Windel, A. Safety and health at work through persuasive assistance systems. In Digital Human Modeling and Applications in Health, Safety, Ergonomics, and Risk Management. Human Body Modeling and Ergonomics; Springer: Berlin/Heidelberg, Germany, 2013; pp. 40-49.

9. Heyer, C. Human-robot interaction and future industrial robotics applications. In Proceedings of the International Conference on Intelligent Robots and Systems, Taipei, Taiwan, 18-22 October 2010; pp. 4749-4754.

10. Moniz, A.B.; Krings, B.-J. Technology assessment approach to human-robot interactions in work environments. In Proceedings of the 7th International Conference on Human System Interactions (HSI 2014), Caparica, Portugal, 16-18 June 2014; pp. 282-289.

11. Sheridan, T.B. Human-Robot Interaction: Status and Challenges. Hum. Factors 2016, 58, 525-532. [CrossRef] [PubMed]

12. Thrun, S. Toward a Framework for Human-Robot Interaction. Human-Comput. Interact. 2004, 19, 9-24. [CrossRef]

13. Prewett, M.S.; Johnson, R.C.; Saboe, K.N.; Elliott, L.R.; Coovert, M.D. Managing workload in human-robot interaction: A review of empirical studies. Comput. Hum. Behav. 2010, 26, 840-856.

14. Heise, R. Demonstration Instead of Programming: Focussing Attention in Robot Task Acquisition; Research Report no. 89/360/22; University of Calgary: Calgary, AB, Canada, 1989.

15. Exploratory Workshop on the Social Impacts of Robotics-Summary and Issues. A Background Paper. Available online: http:/ / ota.fas.org/reports/8209.pdf (accessed on 29 July 2016).

16. Bijker, W.E.; Hughes, T.P.; Pinch, T. The Social Construction of Technological Systems; MIT Press: Cambridge, MA, USA, 1987.

17. Braverman, H. Labor and Monopoly Capital: The Degradation of Work in the Twentieth Century; Monthly Review: New York, NY, USA, 1974.

18. Ennals, R.; Gustavsen, B. Work Organisation and Europe as a Development Coalition; John Benjamins: Amsterdam, The Netherlands, 1999.

19. Fischer, M.; Lehrl, W. Industrieroboter-Entwicklung und Anwendung im Kontext von Politik, Arbeit, Technik und Bildung; Donat: Bremen, Germany, 1991. (In German)

20. Ellul, J. La Technique ou l'Enjeu du Siècle; Collection Sciences Politiques: Armand Colin, Paris, France, 1954. (In French)

21. Blauner, R. Alienation and Freedom; University of Chicago: Chicago, IL, USA, 1964.

22. Kern, H.; Schumann, M. Das Ende der Arbeitsteilung? Rationalisierung in der industriellen Produktion: Bestandsaufnahme, Trendbestimmung (The End of the Division of Labour? Rationalization in Industrial Production: StockTaking and Trend Determination); Verlag C.H. Beck: Munich, Germany, 1984. (In German)

23. Corbett, J.M.; Rasmussen, L.B.; Rauner, F. Crossing the Border. The Social and Engineering Design of Computer Integrated Manufacturing Systems; Springer: London, UK, 1991.

24. Frey, C.B.; Osborne, M.A. The Future of Employment: How Susceptible Are Jobs to Computerisation; Oxford Martin School: Oxford, UK, 2013.

25. Greenan, N.; Kocoglu, Y.; Walkowiak, E.; Csizmadia, P.; Makó, C. The Role of Technology in Value Chain Restructuring; Katholieke Universiteit: Leuven, Belgium, 2009.

26. Huws, U., Ed.; The Transformation of Work in a Global Knowledge Economy: Towards a Conceptual Framework; WORKS: Leuven, Belgium, 2006.

27. Huws, U.; Dahlmann, S.; Flecker, J.; Holtgrewe, U.; Schönnauer, A.; Ramioul, M.; Geurts, K. Value Chain Restructuring in Europe in a Global Economy; Katholieke Universiteit: Leuven, Belgium, 2009.

28. Anderson, R.L.; Gartner, W.B. When robots and people work together. Robotics 1985, 1, 69-76.

29. Bernstein, D.; Crowley, K.; Nourbakhsh, I. Working with a robot: Exploring relationship potential in human-robot systems. Interact. Stud. 2007, 8, 465-482.

30. Cypher, A.I. Watch What I Do: Programming by Demonstration; MIT Press: Cambridge, MA, USA, 1993. 
31. Laessoe, J.; Rassmussen, L. Human-Centered Methods-Development of Computer-Aided Work Processes; Esprit-Project 1217(1199); Tekniske Hojskole Kongena: Lyngby, Danmark, 1989.

32. Moniz, A.B. Anthropocentric-based robotic and autonomous systems: Assessment for new organisational options. In Robo- and Informationethics: Some Fundamentals; Decker, M., Gutmann, M., Eds.; LIT: Zurich, Switzerland, 2012; pp. 123-157.

33. Ritter, H., Ed.; Human Centered Robot Systems. Cognition, Interaction, Technology; Springer: Berlin/Heidelberg, Germany, 2009.

34. Krings, B.-J. Arbeit und Technik. In Handbuch Technikethik; Grunwald, A., Ed.; Metzlerpp: Stuttgart \& Weimar, Germany, 2013; pp. 217-222.

35. Sandberg, T. Work Organization and Autonomous Groups; LiberFörlag: Lund, Sweden, 1982.

36. Van den Besselaar, P., Clement, A., Jarvinen, P., Eds.; Information System, Work and Organization Design; North-Holland: Amsterdam, The Netherlands, 1991.

37. Gorle, P.; Clive, A. Positive Impact of Industrial Robots on Employment; IFR/Metra Martech: London, UK, 2011.

38. IFR-International Federation of Robotics. World Robotics 2015; IFR: Frankfurt, Germany, 2015.

39. Moniz, A.B.; Krings, B.-J.; van Hootegem, G.; Huys, R. Technological practices in the European auto industry: Exploring cases from Belgium, Germany and Portugal. Int. J. Automot. Technol. Manag. 2002, 2, 84-100.

40. Chart of the Week: 54\% of EU Jobs at Risk of Computerisation. Available online: http://bruegel.org/2014/ 07/chart-of-the-week-54-of-eu-jobs-at-risk-of-computerisation/ (accessed on 8 July 2016).

41. Gorle, P.; Clive, A. Positive Impact of Industrial Robots on Employment: Updated in January 2013 to Take Account of More Recent Data; IFR/Metra Martech: London, UK, 2013.

42. Corbett, J.M. Human Centred Advanced Manufacturing Systems: From Rhetoric to Reality. Int. J. Ind. Ergon. 1990, 5, 83-90.

43. Ramioul, M. Organisational change and the demand for skills. In The Transformation of Work in a Global Knowledge Economy: Towards a Conceptual Framework; Huws, U., Ed.; WORKS: Leuven, Belgium, 2006; pp. 97-118.

44. Miller, B.; Atkinson, R.D. Are Robots Taking Our Jobs, or Making Them? Available online: http://www2.itif. org/2013-are-robots-taking-jobs.pdf (accessed on 29 July 2016).

45. Barattini, P.; Wögerer, C.; Robertson, N.; Morand, C.; Pichler, A.; Rovetta, A.; Corradini, A.; Samani, H.; Hopgood, J.; Almajai, I. In the Reference Proposal to the Workshop on Human Interaction with Industrial Collaborative Autonomous Robots. In Proceedings of the 2012 Conference on RO-Man, Paris, France, 9-13 September 2012.

46. EUROP. Robotic Visions to 2020 and beyond-The Strategic Research Agenda for Robotics in Europe. Available online: http://www.eurosfaire.prd.fr/7pc/doc/1286200019_g44_geoffpegman.pdf (accessed on 29 July 2016).

47. Moniz, A.B. Redesigning Work Organizations and Technologies: Experiences from European Projects. Available online: https:/ /ideas.repec.org/p/pra/mprapa/6170.html (accessed on 29 July 2016).

48. OCED. The Future of Productivity; OECD Publishing: Paris, France, 2015.

49. Jäger, A.; Cornelius, M.; Oliver, S.; Zanker, C. Analysis of the Impact of Robotic Systems on Employment in the European Union; Publications Office of the European Union: Luxembourg, Luxembourg, 2015.

50. Brödner, P.; Latniak, E. Sources of Innovation and Competitiveness: National Programmes Supporting the Development of Work Organisation. Available online: http://www.iat.eu/aktuell/veroeff/ps/broedner02c. pdf (accessed on 29 July 2016).

51. Vasic, M.; Billard, A. Safety issues in human-robot interaction. In Proceedings of IEEE International Conference on Robotics and Automation, Karlsruhe, Germany, 6-10 May 2013; pp. 197-204.

52. Lenz, C. Context-Aware Human-Robot Collaboration as a Basis for Future Cognitive Factories. Ph.D. Thesis, Technische Universität München, Munich, Germany, 2011.

53. Prassler, E., Lawitzky, G., Stopp, A., Grunwald, G., Hägele, M., Dillmann, R., Iossifidis, I., Eds.; Advances in Human-Robot Interaction; Springer: Berlin/Heidelberg, Germany, 2005.

54. Wagner, J.J.; van der Loos, H.F.; Leifer, L.J. Construction of social relationships between user and robot. Robot. Auton. Syst. 2000, 31, 185-191.

55. Dario, P.; Guglielmelli, E.; Genovese, V.; Toro, M. Robot assistants: Applications and evolution. Robot. Auton. Syst. 1996, 18, 225-234. 
56. Albu-Schäffer, A.; Haddadin, S.; Ott, C.; Stemmer, A.; Wimböck, T.; Hirzinger, G. The DLR lightweight robot: Design and control concepts for robots in human environments. Ind. Robot Int. J. 2007, 34, 376-385.

57. Kaiser, M. A Framework for the Generation of Robot Controllers from Examples. In Proceedings of the 10th ISPE/IFAC International Conference on CAD/CAM, Robotics and Factories of the Future, Ottawa, ON, Canada, 21-24 August 1994; IFAC: Ottawa, ON, Canada.

58. Kochan, A. Robots and operators work hand in hand. Ind. Robot Int. J. 2006, 33, 422-424.

59. Krüger, J.; Lien, T.K.; Verl, A. Cooperation of human and machines in assembly lines. CIRP Ann. Manuf. Technol. 2009, 58, 628-646.

60. Kobayashi, Y.; Onishi, M.; Hosoe, S.; Luo, Z. Multi-tasking arbitration and behaviour design for human-interactive robots. Int. J. Syst. Sci. 2013, 44, 795-811.

61. Medeiros, D.; Sadowski, R. Simulation of robotic manufacturing cells: A modular approach. Simulation 1983, 40, 3-12.

62. Nee, A.Y.C.; Ong, S.K.; Chryssolouris, G.; Mourtzis, D. Augmented reality applications in design and manufacturing. CIRP Ann. Manuf. Technol. 2012, 61, 657-679.

63. Drury, J.L.; Scholtz, J.; Yanco, H.A. Applying CSCW and HCI Techniques to Human-Robot Interaction. Available online: http:/ / robotics.cs.uml.edu/fileadmin/content/publications/2004/drury-scholtz-yancochi04-wkshp.pdf (accessed on 29 July 2016).

64. Mayer, M.; Odenthal, B.; Faber, M.; Winkelholz, C.; Schlick, C. Cognitive Engineering of Automated Assembly Processes. Hum. Factors Ergon. Manuf. Serv. Ind. 2014, 24, 348-368.

65. Mohs, C.; Naumann, A.; Meyer, H.A.; Pohlmeyer, A. IUUI-Intuitive Use of User Interfaces. In Usability Professionals 06; Chapter der Usability Professionals' Association: Stuttgart, Germany, 2006.

66. Tsarouchi, P.; Makris, S.; Chryssolouris, G. Human-robot interaction review and challenges on task planninand programming. Int. J. Comput. Integr. Manuf. 2016, 29, 916-931.

67. Das, A.; Jayaram, J. Socio-technical perspective on manufacturing system synergies. Int. J. Prod. Res. 2007, 45, 169-205.

68. Kiesler, S.; Hinds, P. Introduction to this special issue on Human-Robot Interaction. Hum. Comput. Interact. 2004, 19, 1-8.

69. Moniz, A.B. Intuitive interaction between humans and robots in work functions at industrial environments: The role of social robotics. In Social Robots from a Human Perspective; Springer: Cham, Switzerland, 2015; pp. 67-76.

70. Unmanned Systems Integrated Roadmap FY2011-2036. Available online: http://www.acq.osd.mil/sts / docs/Unmanned\%20Systems\%20Integrated\%20Roadmap\%20FY2011-2036.pdf (accessed on 29 July 2016).

71. Colombo, D.; Dallefrate, D.; Tosatti, L.M. PC Based Control Systems for Compliance Control and Intuitive Programming of Industrial Robots. Available online: http:/ / www.smerobot.org/08_scientific_papers/\#2006 (accessed on 12 July 2016).

72. Lenz, C.; Nair, S.; Rickert, M.; Knoll, A.; Rosel, W.; Gast, J.; Bannat, A.; Wallhoff, F. Joint-action for humans and industrial robots for assembly tasks. In Proceedings of the 17th IEEE International Symposium on Robot and Human Interactive Communication (RO-MAN 2008), Munich, Germany, 1-3 August 2008.

73. Morioka, M.; Sakakibara, S. A new cell production assembly system with human-robot cooperation. CIRP Ann. Manuf. Technol. 2010, 59, 9-12.

74. Barthélemy, J.P.; Bisdorff, R.; Coppin, G. Human centred processes and decision support systems. Eur. J. Oper. Res. 2002, 136, 233-252.

75. Akan, B.; Ameri, A.; Cürüklü, B.; Asplund, L. Intuitive Industrial Robot Programming through Incremental Multimodal Language and Augmented Reality. In Proceedings of the 2011 IEEE International Conference on Robotics and Automation, Shanghai, China, 9-13 May 2011.

76. Haddadin, S.; Suppa, M.; Fuchs, S.; Bodenmüller, T.; Albu-Schäffer, A.; Hirzinger, G. Towards the Robotic Co-Worker. In Robotics Research; Pradalier, C., Siegwart, R., Hirzinger, G., Eds.; Springer: Berlin/Heidelberg, Germany, 2011; pp. 261-282.

77. Hinds, P.J.; Roberts, T.L.; Jones, H. Whose job is it anyway? A study of Human-Robot Interaction in a collaborative task. Hum. Comput. Interact. 2004, 19, 151-181.

78. Eason, K.D. Representing socio-technical systems options in the development of new forms of work organization. Eur. J. Work Organ. Psychol. 1996, 5, 399-420. 
79. Groom, V.; Takayama, L.; Ochi, P.; Nass, C. I Am My Robot: The Impact of Robot-building and Robot Form on Operators. In Proceedings of the 4th ACM/IEEE International Conference on Human Robot Interaction (HRI '09), San Diego, CA, USA, 11-13 March 2009.

80. Weiss, A.; Wurhofer, D.; Lankes, M.; Tscheligi, M. Autonomous vs. tele-operated: How people perceive human-robot collaboration with HRP-2. In Proceedings of the 4th ACM/IEEE International Conference on Human Robot Interaction, San Diego, CA, USA, 11-13 March 2009; pp. 257-258.

81. Kock, S.; Vittor, T.; Matthias, B.; Jerregard, H.; Källman, M.; Lundberg, I.; Hedelind, M. A Robot Concept for Scalable, Flexible Assembly Automation: A technology study on a harmless dual-armed robot from ABB. In Proceedings of the IEEE ISAM 2011 International Symposium on Assembly and Manufacturing, Tampere, Finland, 25-27 May 2011.

82. Ribeiro, L.; Barata, J.; Barreira, P. Is Ambient Intelligence a truly Human-Centric Paradigm in Industry? Current Research and Application Scenario. Available online: https://run.unl.pt/handle/10362/4098 (accessed on 29 July 2016).

83. Schraft, R.D.; Meyer, C. The need for an Intuitive Teaching Method for Small and Medium Enterprises. VDI Ber. 2006, 1956. [CrossRef]

84. Moniz, A.B. The Collaborative Work Concept and the Information Systems Support: Perspectives for and from Manufacturing Industry. Technikfolgenabschätzung-Theorie und Praxis 2007, 16, 49-57.

85. Jara, C.A.; Candelas, F.A.; Gil, P.; Fernández, M.; Torres, F. An augmented reality interface for training robotics through the web. Available online: https://rua.ua.es/dspace/bitstream/10045/10163/1/Paper_ ISR09_Proc.pdf (accessed on 29 July 2016).

86. Interactions between New Technologies and the Job Market, Flexicurity and Training/Vocational Training. Available online: http:/ /www.itas.kit.edu/pub/v/2007/krmu07a.pdf (accessed on 29 July 2016).

87. Paulos, M.R.; Moniz, A.B. Fragmentation? The future of work in Europe in a global economy: The WORKS final International Conference debate. Enterp. Work Innov. Stud. 2008, 4, 167-169.

88. Krings, B.-J. Global restructuring and its effects on occupations: Towards a new division of labor? In Proceedings of the International Confence DFG Graduate School Topology of Technology, Darmstadt, Germany, 30-31 October 2008.

89. Tranfield, D.; Smith, S.; Ley, C.; Bessant, J.; Levy, P. Changing organizational design and practices for computer integrated technologies. Int. J. Technol. Manag. 1991, 6, 211-221.

90. Wallhoff, F.; Blume, J.; Bannat, A.; Rösel, W.; Lenz, C.; Knoll, A. A skill-based approach towards hybrid assembly, Adv. Eng. Inform. 2010, 24, 329-339.

91. Münch, S.; Kreuziger, J.; Kaiser, M.; Dillmann, R. Robot programming by demonstration—Using machine learning and user interaction methods for the development of easy and comfortable robot programming systems. In Proceedings of the International Symposium on Industrial Robots (ISIR '94), Hannover, Germany, 25-27 April 1994; pp. 685-693.

92. Rogalla, O.; Ehrenmann, M.; Zöllner, R.; Becher, R.; Dillmann, R. Using gesture and speech control for commanding a robot assistant. In Proceedings of the IEEE International Workshop on Robot and Human Interactive Communication, Berlin, Germany, 27 December 2002; IEEE: Piscataway, NJ, USA, 2002; pp. 454-459.

93. Marin, R.; Sanz, P.; Sanchez, J. A very high level interface to teleoperate a robot via Web including augmented reality. In Proceedings of the 2002 IEEE International Conference on Robotics and Automation, Washington, DC, USA, 11-15 May 2002; pp. 2725-2730.

94. The Role of Autonomy in DOD Systems. Available online: http://www3.nd.edu/ dhoward1/autonomy.pdf (accessed on 29 July 2016).

95. Huws, U. Working online, living offline: Labour in the Internet Age. Work Organ. Labour Glob. $2013,7$. [CrossRef]

96. Ribeiro, L.; Barata, J. New Shop Floor Control Approaches for Virtual Enterprises. Enterp. Work Innov. Stud. 2006, 2, 25-32.

(C) 2016 by the authors; licensee MDPI, Basel, Switzerland. This article is an open access article distributed under the terms and conditions of the Creative Commons Attribution (CC-BY) license (http://creativecommons.org/licenses/by/4.0/). 